\title{
Family ownership, altruism and agency costs in Australian small and medium-sized enterprises
}

\author{
Dong Xianga, ${ }^{a}$, Andrew C. Worthington ${ }^{\mathrm{b}}$ and Helen Higgs ${ }^{\mathrm{b}}$

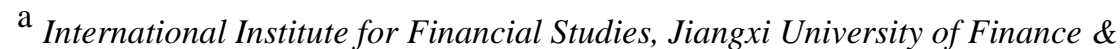 \\ Economics, Nanchang, Jiangxi 330013, China \\ ${ }^{b}$ Department of Accounting, Finance and Economics, Griffith University, Nathan, \\ QLD 4111, Australia
}

\begin{abstract}
Given the continuing uncertainty about whether family firms enjoy lower agency costs, this paper hypothesizes that a combination of the effects of family ownership, altruism and self-control is instead at play. To begin with, family ownership can indeed reduce agency costs through better aligning the interests of owners and managers. This is a 'determining' effect in that it independently mitigates one source of agency problems. However, altruism combined with self-control problems arising from the highly concentrated ownership often found in family firms can also increase agency costs. This is an 'embedding' effect as it is rooted in the personal relationships within the family firm. Using the Business Longitudinal Database compiled by the Australian Bureau of Statistics on small and medium-sized enterprises (SMEs), we find that for larger SMEs (those with 20-200 employees), the gains in lower agency costs arising from family ownership are almost completely offset by the losses from altruism and the lack of selfcontrol.
\end{abstract}

Keywords: agency costs; altruism; self-control; family firms; small and medium-sized enterprises

JEL Classification: C25; G32; L21

\section{Acknowledgements}

The authors would like to thank the editor (Mark Taylor), two anonymous referees, and delegates at the $25^{\text {th }}$ Annual Australasian Finance and Banking Conference for their helpful comments and suggestions.

\footnotetext{
* Corresponding author. E-mail: donxiang@gmail.com
} 


\section{Introduction}

Agency costs arise in the firm from the separation of ownership and control. On this basis, the ideal structure of ownership for zero agency costs is a single owner controlling all aspects of the firm (Jensen and Meckling, 1976). Putting aside this theoretical optimum, agency costs typically vary with the degree of inconsistency in the relation between the ownership and control of a firm and/or the degree of ownership dispersion (Ang et al., 2000). One particular ownership structure of relevance is family-owned firms. Because these firms typically involve family members with both a large share of ownership and both direct and indirect involvement in the management of the firm, the belief is that these structures help resolve the agency problems that exist in other more widely held firms, thereby easing the classic owner-manager conflict (Fama and Jensen, 1985; Steijver and Voordeckers 2009).

However, agency costs may still concern family firms because the alignment of interests between owner and manager can be at the expenses of debt holders (Niskanen and Niskanen, 2010). More importantly, altruism and problems with self-control can even arguably increase agency costs in family firms (Schulze et al., 2001; Burkart et al., 2003; Schulze et al 2003a; Sharma, 2004; Lubatkin et al., 2005). For example, altruism can create a sense of entitlement among family members by encouraging CEOs (usually a parent and/or head of the controlling family) to use the firm's resources to provide family members with employment, perquisites, and privileges that they would not otherwise receive (Schulze et al., 2003b). Altruism can also hamper the ability of the CEO to monitor and discipline offspring and other relatives employed in the family firm.

These already negative effects of altruism arising from concentrated family owner-manager structures can worsen through entanglement with the problem of self-control. We regard these self-control problems as “agency problems with one’s self” (Thaler and Shefrin, 1981). Therefore, some sorts of agency problems that are at least partly addressed in publicly listed firms can be more problematic in family firms especially when small because of variations in the rational assumption of wealth maximization. Consequently, family-owned firms are more vulnerable to both the negative effects of altruism and any complications arising from the entangled problem of self-control. Because concentrated control thus almost grants unchallenged discretion in the use of the firm's assets, family firms often do not have to justify their decisions to an independent board of directors and their shareholders, nor do they have their performance monitored by external stakeholders.

Using a detailed survey of 2,732 Australian small and medium-sized enterprises (SMEs), we find that whether family firms indeed display a lower level of agency costs is itself determined by a combination of the 'determining' effect of family ownership and the 'embedding' effect of altruism. In particular, we find that larger SMEs (those with 20-200 employees) exhibit a significant embedding effect, such that the benefits of reduced agency costs from family ownership are more than offset by the problem of self-control. This suggests that in the interests of organizational efficiency, as SMEs become very large, it becomes increasingly desirable for the bond of family ownership to be dissolved, to be replaced by other mechanisms for reducing agency costs, including the markets for corporate control and managerial talent and the monitoring efforts of debt holders and other stakeholders. Further, in response to the argument about whether family firms indeed have a lower level of agency costs, we suggest that this is in fact determined by a complex combination of the effects of agency relationships, family ownership and altruism. We find that given the effect of family ownership is determined, 
altruism is contingent on the features of family firms, and so the level of agency costs in the family firm is largely dependent on the impact of the altruism effect, not family ownership per se.

The remainder of the paper is organized as follows. In Section II, we discuss our theoretical framework and derive the testable hypotheses. Section III presents the sample and the methodology employed and Section IV discusses the results. Section V provides some concluding remarks.

\section{Theory and hypotheses}

\section{The influence of family ownership on agency costs}

Agency costs arise from an agency relationship in which the interests of the firm's managers and its shareholders do not completely align. As discussed by Jensen and Meckling (1976), agency costs are the sum of monitoring costs, bonding costs and residual loss. First, concerned about the status of the agency relationship, a principal can seek to establish appropriate incentives for the agent, and thus incur monitoring costs, or can pay the agent to expend resources appropriately, known as bonding costs. Second, “...there will be some divergence between the agent's decisions and those decisions which would maximize the welfare of the principal” (Jensen and Meckling 1976, p. 308), referred to as residual loss. For example, a manager that owns less than the entire firm may have an incentive to consume perquisites instead of maximizing the value of the firm to all shareholders, or may avoid some of the difficult decisions required for optimal firm performance. Typically, as the number of non-manager shareholders increases, aggregate expenditure on monitoring declines because of free riding, thus the magnitude of owner-manager agency cost problems can increase in firms with diversified ownership (Ang et al., 2000).

Given agency costs principally arise from the separation of the ownership and management of the firm, owner-manager involvement, as typified in many family businesses, should in principle consolidate the firm and thereby reduce agency costs (Fama and Jensen, 1985). For example, family firms could reduce monitoring costs because of the familiarity and intimate knowledge of business operations gained from long association with the firm, and the facilitation of communication and promotion of cooperation between family owners and family agents (Schulze et al., 2003b). Further, the kinship networks in family firms are generally characterized by norms of reciprocity, strong social ties, a shared identity, and a common history. These can also reduce bonding and residual costs. Lastly, owner-manager or family-controlled SMEs may have a desire for control and so exhibit greater aversion to the use of external equity. Therefore, external equity seeking is less likely to be a consideration for older family business owners and owners that have a strong preference for retaining family control (Romano et al., 2000).

In this sense, family SMEs may entail the mitigation of agency costs because they typically display less dispersion of ownership. For example, using a dataset of small US businesses, Ang et al. (2000) concluded that agency costs were higher when an outsider managed the firm, higher with an increase with the number of nonmanager shareholders, and lower with an increase in the manager's share of ownership. Fleming et al. (2005) reports a similar phenomenon in the context of Australian SMEs. Accordingly, we propose the following hypothesis: 
Hypothesis 1 Family ownership can reduce agency costs through mitigating the conflicts of interests arising from the separation of ownership and control.

\section{Altruism and self-control problems in the family firm}

Despite these considerations, the extant literature argues that family firms are anything but immune to agency problems because of the presence of problems associated with altruism and self-control (Schulze et al., 2001; Burkart et al., 2003; Schulze et al., 2003b; Sharma, 2004; Lubatkin et al., 2005). Altruism—a moral value that motivates individuals to undertake actions that benefit others without any expectation of external reward by theologians (Batson, 1990), a trait or preference that is endogenous to man's character and based on feelings, instincts and sentiments by sociologists (Lunati, 1997), or a utility function in which the welfare of one individual is positively linked to the welfare of others (Bergstrom, 1989)—can provide a powerful and selfreinforcing incentive to allow one individual to take efforts to maximize their own utility by simultaneously satisfying both altruistic (other-regarding) and egoistic (self-regarding) motives (Schulze et al., 2003b).

Therefore, altruism can alter the incentive structure in a family firm such that free riding and other agency problems offset some of the agency benefits gained (Schulze et al., 2001). Altruism thus creates a sense of entitlement among family members by encouraging CEOs to use the firm's resources to provide family members with employment, perquisites, and privileges that they would not otherwise receive (Schulze et al., 2003b). Altruism can also hamper the ability of the CEO to monitor and discipline children and other relatives employed in the family firm. Thus, the owner-manager style of family firms does not necessarily minimize agency costs, and indeed may make them worse. Therefore, while in a nonfamily firm fractional ownership gives insiders an incentive to free ride on the equity of outside owners, in a family firm a family member may also have an incentive to free ride on the controlling owner's equity. Parents thus face a "Samaritan's dilemma" (Buchanan, 1983) in which their actions give their beneficiaries an incentive to take actions or make decisions that may harm their own welfare (Schulze et al., 2003a).

Even worse, the negative effects of concentrated family owner-management arising from altruism can be worsened further through the entanglement with the problem of self-control or "agency problems with one's self” (Thaler and Shefrin, 1981). For instance, Lubatkin et al. (2005) argue that self-control problems arise in family firms because the owner-manager has both the ability and authority to use the firm's resources as they see fit, which also gives them the incentive to advance their personal wellbeing at the expense of other stakeholders. Therefore, self-control problems arise because individuals lack complete foresight and are not fully rational or perfectly disciplined. Given the shares of private or family firms are held primarily by insiders, most of whom are members of the governing board and the management team, and most likely concentrated in the hands of a single owner-manager, the controlling owner, who is usually the CEO and very often the founder, the problem of self-control can be more prevalent among private firms, especially family SMEs, because of the informational asymmetry by which they are characterized. These issues can engender conflicts not only because of moral hazard, but also because of hold-up and adverse selection, both of which are adequately addressed in Jensen and Meckling's model (Lubatkin et al., 2005). For example, when CEOs are also a family member holding a significant share of ownership of the firm, they will assume high risks. This is because the likelihood of being fired is very low when the CEO makes a critical mistake. However, the asset value of the firm will fall as a 
result (Carrasco-Hernandez and Sanchez-Marin, 2007). Losses of this kind well illustrate the issue of hold-up as it relates to altruism in the family firm.

Some sorts of agency problems partly addressed in publicly listed firms can also be more problematic in family firms (especially SMEs) because of the innate variation in the assumption of rational wealth maximization. As suggested by behavioural economists, individuals are motivated by an idiosyncratic set of tastes and preferences e.g. some economic and others non-economic in character, and are driven to maximize the utility they gain from each (Lunati, 1997). Dyer (2006) suggests that several family factors may contribute to low performance, comprising inefficiencies in terms of the utilization of resources as well as the accomplishment of organizational goals. For instance, the minority owners may have an incentive to free ride on the controlling owners' equity by shirking, through exorbitant compensation, or by accumulating perquisites. Thus, family members are not pulling the firm forward, instead, are fighting for their own interests. Under these circumstances, altruism in combination with self-control problems can play a critical role in family business objectives and goals. Therefore, wealth creation is probably not necessarily the only nor even the primary goal of all family businesses (Davis and Tagiuri, 1989; Sharma et al., 1997), and we can always argue that family firms generally include both economic and non-economic goals (Chrisman et al., 2004). Of course, we can also argue that non-economic or altruistic goals do not involve agency issues as long as the utility of the family business owner is maximized. However, these goals can still incur serious agency problems arising from the conflicts of interests between other stakeholders e.g. creditors and management. In other words, altruistic goals only can be achieved at the expense of other stakeholders.

Consequently, family-owned firms are more vulnerable to the negative effects of altruism and the entangled problems of self-control. Because of concentrated control and the almost unchallenged discretion over the use of the firm's assets, family firms do not need to justify their decisions to an independent board of directors or their shareholders, nor do they have their performance monitored by external stakeholders. Put differently, the family firm's controlling owners are faced with an incentive to make decisions that may inadvertently lead to a misalignment of goals among the firm's minority insiders (Lubatkin et al., 2005). To mitigate the agency problems in the family firm, compensation is thus designed to help principals control and reduce agency problems and co-align preferences between parties (Fama and Jensen, 1985). In fact, several studies suggest that contrary to traditional agency cost theory, firm performance is positively related to CEO compensation in private family firms (e.g. Michiels et al., 2012; Combs et al. 2010; Carrasco-Hernandez and Sanchez-Marin, 2007). Drawing on these perspectives, we propose the following hypothesis,

Hypothesis 2 Altruism incurs agency problems arising from the conflict of interests between stakeholders and management in family firms, which can be further exacerbated by the self-control problem arising from informational opaqueness and the possibly large deviations from the business goal of wealth maximization in family SMEs.

\section{Determining and embedding effects}

Altruism and the entangled self-control problems are therefore embedded in the relationships within the family firm, especially the relationships between the controlling owner and other family members. It thus has a contingent effect on the agency problems of the family firm. First, the influence of altruism on agency problems is mediated by the "model of man” (Gorbetta and Salvato, 2004). The underlying model of man agency problem is that being a self-serving individual, a rational owner will seeks to maximize his or her individual 
utility (Jensen and Meckling, 1976), whereas with an other-regarding individual, the behaviour of the owner is ordered such that pro-organizational, collectivistic behaviours have higher utility than individualistic, selfserving behaviours (Davis et al., 1997). Put differently, the influence of altruism is largely contingent on the degree of altruism. A high degree of altruism influences individual conduct in family firms, “...thereby tempering the exercise of authority based on institutional power and high power distance, both conducive to agency problems” (Gorbetta and Salvato, 2004, p. 358).

Second, because family firms are not homogeneous, altruism relies on family firm structure and type. The family firm is often defined according to the degree of family presence in firm ownership (e.g. Filatotchev et al., 2005; Favero et al., 2006; Kowalewski et al., 2010), or a combined ownership/management criterion (Maury, 2006). One classification identifies three types of family firms, the founder-centred family firm, the sibling or cousin consortium family firm, which is still fully owned and managed by the family, and the open family firm, in which both ownership and control are partially shared with non-family shareholders and professional managers (Salvato, 2002). When, for example, owner-management is concentrated in an individual, usually a parent and founder in the case of founder-based family firms, the dark side of parental altruism can exacerbate the agency problems of moral hazard, adverse selection and hold-up that exist in the family firm discussed earlier. At the other end of the spectrum, if owner-management is shared with family and non-family members alike, the negative effects of altruism may be mitigated through alleviating problems with self-control (Lubatkin et al., 2005).

Third, altruism arguably also has a positive side by minimizing the conflicts of interests within the family firm. Altruism first can reduce information asymmetry (the basis of many agency problems) by increasing cooperation and communication within the family firm (Michiels et al., 2012). In addition, communication and some types of decision making can be facilitated by intimate knowledge about each other that family members bring to the family firm (Gersick et al., 1997). Altruism also compels parents to care for their children, encourage family members to be considerate of one another, and makes family membership valuable in ways that both promote and sustain the family bond (Eshel et al., 1998). Therefore, altruism can create a heightened sense of interdependence among family agents, which is an important agency benefit because welfare is directly linked to firm performance through their employment (Schulze et al., 2003b). Lastly, altruism can foster loyalty and ties within the family firm (Ward, 1987), which can make each family member employed by the firm a de facto owner in the sense that they have a residual claim or option on the family's properties (Holtz-Eakin et al., 1993). This claim can further align the interests and preferences within the family firm, and thus limit the source of agency problems (Schulze et al., 2003a).

These two kinds of effects i.e. the determining effect of family ownership and the embedding effect of altruism need to be further addressed in the case of family-owned and professionally-managed firms. With regard to the situation in which a family owned firm has a non-family CEO, the first question is whether or not the family ownership still can reduce agency costs as a determining factor. As a non-family CEO generally has no (very low) ownership of the firm, his/her personal wealth is not essentially tied to firm value (Michiels et al., 2012). Consequently, the agency costs arising from the conflicts of interests between CEO and family owner are expected to prevail (Lubatkin et al., 2005). However, we argue that the family ownership is still a determining factor in reducing the agency costs arising from the conflict of interest between owner and manager. First, when ownership is spread out among a large number of owners, that is, it is a non-family firm; CEOs thus are in a 
situation to protect their personal investment by taking decisions that do not necessarily maximize the shareholders' objective function (Van den Berghe and Carchon, 2003). Agency problems in this instance are very high. Then, when family ownership comes in, the ownership is highly concentrated in the family. This is where the CEO's degree of discretional capacity for working in their own interest is lower, although it is still higher than in the case of a family-owned and managed firm (Carrasco-Hernandez and Sanchez-Marin, 2007). Drawing on these perspectives, we posit,

Hypothesis 3A Family ownership and altruism effect measured by control concentration combine to affect agency costs;

Hypothesis 3B Family ownership is a determining factor in agency costs in the sense of independently mitigating one source of agency problems arising from the conflict of interest between owner and manager, whereas the altruism effect is an embedding factor because it is embedded in the family ownership.

As family ownership may reduce agency costs on one hand, and altruism can increase agency costs on the other, the net effect is an empirical question. However, note that the determining effect of family ownership is not necessarily more powerful than the embedding effect of altruism. Moreover, given that the effect of family ownership is determined whereas that of altruism is contingent, the level of agency costs of a family firm is largely dependent on the level of the altruism effect.

We argue size is a better measure than age to capture these variations in the altruism effect among SMEs, even though the three principal types of family firm directly relate to the firm lifecycle. As suggested by Gersick et al. (1997), the ownership of the family firm generally passes through three broad stages: the controlling owner, the sibling partnership, and the cousin consortium. However, we are unable to use age as a proxy for these different stages. First, there is no a definite cut-off when the founders or siblings pass the business onto other family members. Second, the firm's lifecycle does not allow for the third type of family firm, the open family firm, which we argue is the most likely form for large SMEs. Moreover, large SMEs are more likely to display the dispersion of managerial control associated with a lower level of the altruism effect. Therefore, we posit,

Hypothesis 4 A larger family SME will exhibit greater gains from lower agency costs given its lower level of the altruism effect.

However, as the altruism effect involves using firm resources to maximize the owner's altruistic utility in favour of family members at the expense of other stakeholders, a larger SME has a greater capacity to incur these kinds of costs. In addition, for smaller SMEs, whether there is a single person responsible for the major business operating decisions can be difficult to clarify. For example, a family farm or a small grocery shop with just one or two casual employees may respond to survey that there is a single person in-charge, who may also be the head of a household. By comparison, larger SMEs may have a small board and family or non-family CEOs, which makes it more likely for the altruism effect to arise. Consequently, we also posit,

Hypothesis 5 A smaller family SME will have larger gains from agency costs because of the lower level of the altruism effect. 


\section{Data and methodology}

Sample

In our analysis, we utilize the results of the surveys included in the Business Longitudinal Database (BLD) Expanded Confidentialized Unit Record File (CURF) conducted periodically by the Australian Bureau of Statistics (ABS). The ABS Business Characteristics Survey directly collects the data with the assistance of the Australian Taxation Office and Australian Customs. The BLD follows the earlier ABS development of a Business Longitudinal Survey, which ran from 1994 to 1999, based on which several studies investigated Australian small and medium-sized enterprises from different perspectives. Overall, the BLD aims to increase our understanding of the activities or factors that are relevant to business performance and the business characteristics that are associated with these activities and factors. The BLD comprises two independent samples (referred to as panels) drawn from the population of Australian SMEs, defined in the survey as all businesses employing fewer than 200 persons. The panel used in this analysis was surveyed in 2007. The sample includes approximately 2,732 SMEs as selected from a survey frame created in June 2005 of the population of the then 1,563,857 Australian SMEs.

\section{Research design}

In this paper, we specify a direct measure of agency costs in the form of the expense ratio, defined as the ratio of total expenses less the cost of goods sold, interest expenses and managerial compensation to total sales. This captures excessive expenses associated with agency costs, including the consumption of perquisites (perks). Thus, the agency costs as measured by this ratio are only those incurred at the firm level, including shirking and perquisite consumption by the manager (Ang et al., 2000). Unfortunately, we do not have data available on firm asset utilization as an indirect measure. Therefore, the expense ratio we select to proxy agency costs may underestimate the agency costs arising from residual loss.

We first check the levels of agency costs under the effects of family ownership and control concentration by comparing the discretionary expense ratios between family and non-family SMEs, and firms with and without concentration of control. We then test our five hypotheses employing the following regression model:

$$
\text { COST }=f(\text { variables of interest, control variables) }
$$

where COST is the expense ratio, and the set of explanatory variables comprise the variables of interest and control variables. The variables of interest directly address our hypotheses and comprise two dummy variables. The first, OWNF, takes a value of one for a family business and zero otherwise. SING is a proxy for control concentration which takes a value of one if the firm has a single person who is responsible for making the major decisions on business operations and zero otherwise. Given family firms are considerably more likely than nonfamily firms to allow the CEO and the chairperson roles to be occupied by the same person, we argue that family firms with control concentration are more likely to incur altruism and self-control issues (Bartholomeusz and Tanewski (2006). Therefore, we hypothesize negative and positive signs on the estimated coefficients for OWNF and SING, respectively. 
The second set of explanatory variables is to control for the many other factors that impact upon firm expenses. Similar to Kowalewski et al. (2010), industry is included as a control variable. Several studies suggest the importance of industry on firm behaviour and operations (e.g., Caneghem and Campenhout, 2012; Degryse et al., 2012). For example, Balakrishnan and Fox (1993) conclude that firm effects explain about 52 per cent of the variation in financial expenses with inter-industry differences another 11 per cent. In terms of particular industries, Van der Wijst (1989) argues that the manufacturing industry is capital intensive and requires large investments in fixed assets derived from both debt and equity, while the retail sector needs relatively less short-term debt. To control for the variations in expense ratios across industries, we create a set of industry dummy variables (IAG, IMA, ICO, IWH, IRE, IAC, ITR, ITE, IPR, ICU, IPE) using the two-digit Australian and New Zealand Standard Industry Classification (ANZSIC) subdivisions. The industries included are agriculture, mining, manufacturing, construction, wholesale trade, retail trade, accommodation, transport, communication services, property and business services, cultural and recreation services, and personal services, respectively.

Figures 1, 2 and 3 depict the expense ratio and the proportions of family ownership and single-person control by industry. Of the industries, the highest expense ratios are in property and business services and personnel and other services while the lowest are in wholesale trade and agriculture. With respect to family ownership, family ownership is most common is agriculture and transportation services and less common in property and business services and communication services. Lastly, in terms of the prevalence of single-person control, this is much more evident in transportation and personnel and other services and less evident in property and business services and communication services

\section{<FIGURE 1 HERE> \\ $<$ FIGURE 2 HERE $>$ \\ $<$ FIGURE 3 HERE $>$}

Following Ang et al. (2000), in addition to categorizing SMEs by the number of employees, we specify the logarithm of total sales (SIZE) to control for any within-segment variation. As discussed, age relates to the firm lifecycle. We proxy the age of firms using three age dummy variables that take respective values of one for firms aged less than 5 years ( $E A R), 10$ years to 20 years $(M E D)$, and 20 years or more $(O L D)$, zero otherwise. The reference category is firms aged 5 to 10 years.

We also include innovation-defined as the process of the adoption of internally or externally generated devices, systems, policies, programs, processes, products or services that are new to the adopting organizationas a control variable for two reasons. First, innovation typically involves large capital and operating expenditures. Second, innovation is a proxy for growth opportunities (Rosenbusch et al., 2011). These can significantly influence the structure and strength of the external monitoring and controlling behaviours by stakeholders (e.g. Jensen and Meckling, 1976; Myers, 1977; Fama and French, 2002). The dummy variable, $G R O$, takes a value of one if the business has introduced any new or significantly improved operational or organizational processes, otherwise zero. Profitability acts as a control variable because a profitable firm is expected to spend more on personnel when compared to a non-profitable firm, the effects of which should not 
be mixed with agency costs. $P R O$ takes a value of one if the business experienced an increase in profitability compared to the previous year.

Variable statistics

Table 1 provides summary statistics of the variables used in this paper. Because of missing data owing to respondent omission or errors in sequencing, the samples in 2005, and 2006 and 2007 included 2,029 and 1,834 observations, respectively. About 24.2 per cent of the SMEs are from the agriculture, forestry, and fishing industry. The second-largest group of SMEs in the sample is in the manufacturing industry (16.2 per cent) while the third-largest sample group is from the wholesale trade industry (10.3 per cent). About 30 per cent of SMEs are less than five years old, and 23.3 per cent have been in operation for more than 20 years.

\section{<TABLE 1 HERE >}

Of the SMEs in the sample, 63.2 per cent are family firms and 56.9 per cent have a single person responsible for making major business operation decisions. By comparison, most SMEs do not consider innovation as an important performance target. However, more SMEs introduced new goods, services, or processes during the sample period, about 26.2 per cent. The respondents considered about 12.4 per cent of the SMEs to be more profitable than their major competitors compared with the previous year.

\section{Results}

Table 2 details the mean expense ratios. The mean expense ratio for Australian SMEs ranges from 22.3 to 27.3 per cent for family and non-family SMEs, respectively. By comparison, Ang et al. (2000) suggest a much higher expense-to-sales range for US SMEs ranging between 47 and 52 per cent. Apart from the differences in business practice in the two countries, one reason may be because of different definitions used in calculating the ratios. For example, in our analysis expenses are total salary, wages and other expenses, whereas expenses in Ang et al. (2000) are defined as total expenses less cost of goods sold, interest expense and managerial compensation.

\section{$<$ TABLE 2 HERE $>$}

The apparent difference in the mean expense ratio between family and non-family SMEs is about 5.3 per cent. Given an F-test of the null hypothesis that the two groups have the same variances is rejected with a $p$ value of less than .01 , we assume unequal variances in calculating the $t$-test and find that the difference is statistically significant at the .01 level. That is, on average, family SMEs have expenses about \$133,915 lower than that of a comparable non-family firm. As discussed earlier, we divide the SMEs into three roughly equallysized groups by the number of employees, namely, small SMEs (fewer than 5 employees), medium SMEs (between 5 and 20 employees), and large SMEs (more than 20 and fewer than 200 employees). Note that the ABS does not consider firms with more than 200 employees as SMEs.

For both family and non-family-owned SMEs, the expense ratios increase from small to medium SMEs, and again from medium to large SMEs for family-owned firms, but decrease for non-family-owned SMEs. As a result, the spread in the expense ratio for the small and medium groups of SMEs is approximately the same as the sample as a whole (between 5.1 and 5.2 per cent). However, this narrows appreciably for large SMEs where the spread in favour of family-owned SMEs is only about 2.0 per cent. All of the differences in variances and 
means are statistically significant. Thus, family ownership certainly appears to alleviate agency costs, which gives evidence supportive of Hypothesis 1. However, this effect appears to diminish somewhat with larger family SMEs, implying the possibility of the embedding altruism effect we have discussed.

\section{$<$ TABLE 3 HERE $>$}

To further address the issues of paternal altruism or self-control, Table 3 presents the mean differences among the different categories based on the concentration of control. For the most part, SMEs with a single person responsible for major decisions appear to have a higher expense ratio compared with SMEs without across all sizes, which provides some grounds for Hypothesis 2. However, the differences are only statically significant for large SMEs at the .10 level where the average single-person controlled firm has an expense ratio of 25.2 per cent compared with that in a non-single-person controlled firm of 23.2 per cent. So it appears that Hypothesis 5 but not Hypothesis 4 prevails among Australian SMEs. As discussed, in addition to the determining effect of family ownership, parental altruism can play an important role in the decision-making of a family firm. Altruism can compel the controlling owner to compromise their own first-best option because they also consider the welfare of other family members in the firm. Over time, the economic incentive to do what they can to maximize the utility of family members can blur the controlling owner's perception of what is best for the firm. Furthermore, conflicts also can arise between family members and the controlling family owner and among family members because the family members in the firm may consider their own benefits rather than the benefits of the family-owned firm. In addition, while family member employees, like their counterparts in public firms, bear only a fraction of the risk associated with an investment decision, unlike their counterparts, they are typically entitled to a larger share of any benefits because of their family status. Therefore, altruism entangled with the problem of self-control can arise under these circumstances, especially in large SMEs.

Next, making allowances for potentially influential factors such as industry, size, age, etc. in determining SME expense ratios, we further clarify the effects of family ownership and control concentration on agency costs. Given the dependent variable (the expense ratio) takes a value only between zero and one, a censored regression model, in this case, a Tobit model, is appropriate. Table 4 details the results. The results for four separate models are included. These are identical in terms of the specification of the dependent and control variables, the only differences being the inclusion of the dummy variables for family ownership (OWNF) (Models 1, 3 and 4), control concentration (SING) (Models 2, 3 and 4), and the interaction between family ownership and control concentration $(O W N F \times \operatorname{SING})$ (Model 4) which is used to test the embedding effect of altruism.

\section{$<$ TABLE 4 HERE $>$}

As shown in Table 4, family ownership (OWNF) exerts a consistently and significantly negative effect on expense ratios at the .01 level across all of the models, indicating that family ownership reduces agency costs between 3.0 and 6.1 per cent over a comparable non-family firm. In combination with the results of the univariate analysis in Table 3, Hypothesis 1 has been proven. We then see that in Model 4 the interaction between family ownership and control concentration is positive and statistically significant at the 5 per cent level with a marginal value of 4.3 per cent. This indicates that a family firm with control concentration has a higher level of agency costs by 4.3 per cent compared with a family firm without control concentration. Put 
differently, the altruism effect increases agency costs, even in a family SME, and this supports Hypotheses 2 and 3A. Furthermore, in combination with the insignificant coefficients in Model 2 and 3, altruism is clearly embedded in family ownership, as in Hypothesis 3B. However, the significantly negative coefficient in Model 4 is a bit puzzling, as it appears to contradict Hypothesis 2.

We can interpret this in two ways. First, the control concentration is only an embedding effect not a determining effect. The interactions between control concentration and family ownership are consistently significant at the .05 level across the models, whereas control concentration is not statistically significant in Model 3 in Tables 4 and 5. This evidences the embedding effects of control concentration on agency costs. In other words, the significant effect of SING under control of family ownership means that it can only affect agency costs on its own, which is also consistent with the univariate analysis in Table 3. Second, when we control for both the determining effect of family ownership and the embedding effect of altruism, this negative effect of control concentration could be disturbed by the some specific features in the sample, such as micro (very small) SMEs, as discussed below.

\section{<TABLE 5 HERE>}

In Table 5, we again break down the sample into three groups according to the number of employees. Once again, in small SMEs family ownership exerts a consistently negative effect on agency costs across all four models. The embedding effect proxied by the interaction between family ownership and control concentration has a significantly positive effect on agency costs for large SMEs with a $p$-value of 10 per cent and a marginal effect up to 6 per cent. As family ownership reduces agency costs at the margin by 5 per cent, we conclude that for large SMEs, the gains in reduced agency costs from the negative effects of family ownership on expenses are completely offset by the losses in agency costs from the positive effects of altruism on expenses. This is consistent with Hypotheses 1, 2, 3A and 3B. Further, the embedding effect does not appear to have a significant effect on agency costs among medium-sized SMEs, and this supports Hypothesis 5.

As mentioned, this negative effect of control concentration could be disturbed by the some specific features in micro SMEs. We argue that for a micro business, the response to the question "whether or not the firm is a family firm” could be very vague, in other words, the difference between family firm and non-family firm could be very vague. For those responding "no" the firm could be owned by family or partners. In this sense, the effects of control concentration may be in line with that of family ownership. That is, the significant and negative effect of SING may be interpreted as the effects of family or partner ownership for the micro firms who did say "yes" to whether the business is family firm. This is because compared with large SMEs, micro SMEs with fewer than 5 employees normally have a relatively simple control structure. Under these circumstances, whether there is a single person or several persons responsible for the major business operating decisions can be difficult to clarify. For instance, a family owning a farm or a small grocery shop with just one or two casual employees may respond that there is a single person in-charge (who may also be the head of a household).

As an example, husband-wife business structures are very common in Australian SMEs, especially among tradesmen, contractors and farmers, where the husband is the electrician, plumber, mechanic, painter, farmer, etc., responsible for the core business activities, while the wife looks after support services like bookkeeping, customer service, purchasing, and job scheduling. However, the husband-owner-manager may extensively discuss business decisions with his spouse, who very often is also an equity partner. Therefore, notional control 
concentration may not make any significant difference in terms of the effects of parental altruism and selfcontrol problem on agency costs. This phenomenon is similar to the 'Clan Family Firm' first termed by Dyer (2006), where family control may reduce the agency costs. By comparison, larger SMEs may have a small board, comprising a principal owner who is usually also the principal manager and perhaps founder, and minority shareholder, that are members of a nuclear and/or extended family and often but not always employed by the firm. In this case, the investigation into the embedding effect of control concentration makes more sense.

With respect to the control variables, size and most of the industry dummies are statistically significant. The negative effects of size on the expense ratio suggest that larger firms can benefit from scale economies at a marginal value of 5 per cent. However, firm profitability, age, and growth opportunities do have a significant effect on agency costs.

\section{$<$ TABLE 6 HERE $>$}

Finally, we perform a robustness test by regressing the logarithm of the expense ratio on the independent variables. As the dependent variable is no longer censored between 0 and 1, we use OLS regression. Table 6 reports the results (estimates for industry effects not shown). Compared with the results for Model 4 in Table 5, these estimates are highly consistent. We also note that the models using only the larger SMEs exhibit better fit in terms of adjusted R-squared.

\section{Concluding remarks}

This paper addresses the factors affecting agency costs in SMEs, mainly focusing on the effects of family ownership and altruism. The main finding is that whether family firms display the purportedly lower level of agency costs is determined by a combination of the determining effect of family ownership and the embedding effect of altruism. Family ownership can indeed reduce agency costs through aligning the interests of owners and managers in family firms. This is a determining effect in the sense of independently mitigating one source of agency problems arising from the conflict of interests between owners and managers. However, family firms can incur a problem with altruism which can create a sense of entitlement among family members by encouraging CEOs (usually a parent and/or household head of the controlling family) to use the firm's resources to provide family members with employment, perquisites, and privileges that they would not otherwise receive. Even worse, in the family firm, the altruism effect arising from concentrated control can be further worsened by its entanglement with the problem of self-control. Therefore, the altruism effect can increase agency costs in family firms. Further, as this effect is embedded in the relationships within the family firm, especially between that of the controlling owner and the family member, altruism is an embedding factor in agency costs. For this reason, it is determined by the "model of man" and the structure and type of the family firm.

Given the determining effect of family ownership may reduce agency costs on one hand, whereas the embedding effect of altruism can increase agency costs on the other, whether family firms have a lower or higher level of agency costs is an empirical question. However, given that the effect of family ownership is determined, the altruism is contingent on the features of family firms, thus the level of agency costs in a family firm is largely dependent on the level of the altruism effect. Therefore, an investigation into agency costs is largely dependent on the segmented groups of family firms according to the family firm features. In light of this, by examining Australian SMEs we find that larger SMEs exhibit a significant level of the embedding altruism 
effect. Therefore, the gains in agency costs due to family ownership are completely offset by the losses from the altruism effect.

Of course, this analysis has several limitations. First, we only employ a direct measure of agency costs. Ideally, an indirect measure such as asset utilization or the cash reserve ratio could be used as complements if suitable data were available. Second, we measure both family ownership and control concentration with a binary variable given the nature of the data available. Thus, we are unable to clearly distinguish between the effects of the magnitude of ownership and control dispersion on agency costs. Finally, in this paper we segment the sample by size. However, if we could divide family firms by type or their ownership by model, the results may be more informative.

\section{References}

Ang, S. G., Cole, A. R., and Lin, W. J. (2000) Agency costs and ownership structure, Journal of Finance, 55, 81-106.

Balakrishnan, S., and Fox, I. (1993) Asset specificity, firm heterogeneity and capital structure, Strategic Management Journal, 14, 3-16.

Bartholomeusz, S., \& Tanewski, G. A. (2006) The relationship between family firms and corporate governance, Journal of Small Business Management, 44, 245-267.

Batson, C. D. (1990) How social is an animal? The human capacity for caring, American Psychologist, 45, 336346.

Bergstrom, T. C. (1989) A fresh look at the rotten kid theorem and other household mysteries, Journal of Political Economy, 97, 1138-1159.

Buchanan, J. M. (1983) Rent seeking, non-compensated transfers and laws of succession, Journal of Law and Economics, 26, 71-85.

Burkart, M., Panunzi, F., and Schleifer, A. (2003) Family firms, Journal of Finance, 58, 2167-2201.

Caneghem, T. V, and Campenhout, G. V. (2012) Quantity and quality of information and SME financial structure, Small Business Finance, 39, 341-358.

Carrasco-Hernandez, A. and Sanchez-Marin, G. (2007). The determinants of employee compensation in family firms: Empirical evidence, Family Business Review, 20, 215-228.

Chrisman, J. J., Chua, J. H., and Litz, R. A. (2004) Comparing the agency costs of family and non-family firms: Conceptual issues and exploratory evidence, Entrepreneurship Theory and Practice, 28, 335-354.

Combs, J. G., Penney, C. R., Crook, T. R., and Short, J. C. (2010) The impact of family representation on CEO compensation, Entrepreneurship Theory and Practice, 34, 1125-1144.

Davis, J. A., and Tagiuri, R. (1989) The influence of life-stage on father-son work relationships in family companies, Family Business Review, 2, 47-71.

Davis, J. H., Schoorman, F. D., and Donaldson, L. (1997) Toward a stewardship theory of management, Academy of Management Review, 22, 20-47.

Degryse, H., Goeij, P. D., and Kappert, P. (2012) The impact of firm and industry characteristics on small firms' capital structure, Small Business Economics, 38, 431-447.

Dyer, W. G. (2006) Examining the "family effect" on firm performance, Family Business Review, 19, $253-273$.

Eshel, I., Samuelson, L., and Shaked, A. (1998). Altruists, egoists, and hooligans in a local interaction model, American Economic Review, 88, 157-179.

Fama, E. F., and French, K. R. (2002) Testing trade-off and pecking order predictions about dividends and debt, Review of Financial Studies, 15, 1-33. 
Fama, E. F., and Jensen, M. C. (1985) Organisational firms and investment decisions, Journal of Financial Economics, 14, 101-119.

Favero, C. A., Giglio, S., Honorati, M., and Panunzi, F. (2006) The performance of Italian family firms, European Corporate Governance Institute Working Paper Series in Finance, No. 127/2006.

Filatotchev, I., Lien, Y. Ch., and Piesse. J. (2005) Corporate governance and performance in publicly listed, family-controlled firms: Evidence from Taiwan, Asia Pacific Journal of Management, 22, 257-283.

Fleming, G., Heaney, R., and McCosker, R. (2005) Agency costs and ownership structure in Australia, PacificBasin Finance Journal, 13, 29-52.

Gersick, K. E., Davis, J. A., Hampton, M. M., and Lansberg, H. (1997), Generation to Generation: Life Cycles of the Family Business, Harvard Business School Press, Cambridge, MA.

Gorbetta, G., and Salvato, C. (2004). Self-serving or self-actualizing? Models of man and agency costs in different types of family firms: A commentary on "Comparing the agency costs of family and non-family firms: Conceptual issues and exploratory evidence”. Entrepreneurship Theory and Practice, 28, 355-362.

Holtz-Eakin, D., Joulfian, D., and Rosen, H. S. (1993) The Carnegie conjecture: Some empirical evidence, Quarterly Journal of Economics, 108, 413-435.

Jensen, M. C., and Meckling, W. H. (1976) Theory of the firm: Managerial behaviour, agency costs, and ownership structure, Journal of Financial Economics, 3, 305-360.

Kowalewski, O., Talavera, O., and Stetsyuk , I. (2010) Influence of family involvement in management and ownership on firm performance: Evidence from Poland, Family Business Review, 23, 45-59.

Lubatkin, M. H., Schulze, W. S., Ling, Y., and Dino, R. N. (2005) The effects of parental altruism on the governance of family-managed firms, Journal of Organizational Behaviour, 26, 313-330.

Lunati, M. T. (1997) Ethical Issues in Economics: From Altruism to Cooperation to Equity. London: Macmillan.

Maury, B. (2006) Family ownership and firm performance: Evidence from western European corporations, Journal of Corporate Finance, 12, 321-341.

Michiels, A., Voordeckers, W., Lybaert, N., and Steijvers, T. (2012) CEO compensation in private family firms: pay-for-performance and the moderating role of ownership and management, Family Business Review, 20, $1-20$.

Myers, S. C. (1977) Determinants of corporate borrowing, Journal of Financial Economics, 5, 147-175.

Niskanen, M., and Niskanen, J. (2010). Small business borrowing and the owner-manager agency costs: Evidence on Finnish data. Journal of Small Business Management, 48, 16-31.

Romano, C. A., Tanewski, G. A., and Smyrnios, K. X. (2000) Capital structure decision making: A model for family business, Journal of Business Venturing, 16, 285-310.

Rosenbusch, N., Brinckmann, J., and Bausch, A. (2011) Is innovation always beneficial? A meta-analysis of the relationship between innovation and performance in SMEs, Journal of Business Venturing, 26, 441-457.

Salvato, C. (2002) Antecedents of entrepreneurship in three types of family firms, Jonkoping International Business School, Research Report 1/2002.

Schulze, W., Lubatkin, M., \& Dino, R. (2003a) Exploring the agency consequences of ownership dispersion among the directors of private family firms, Academy of Management Journal, 46, 179-194.

Schulze, W., Lubatkin, M., \& Dino, R. (2003b) Toward a theory of agency and altruism in family firms, Journal of Business Venturing, 18, 473-490.

Schulze, W., Lubatkin, M., Dino, R., and Buchholtz, A. (2001) Agency relationships in family firms: Theory and evidence, Organization Science, 12, 99-116.

Sharma, P. (2004). An overview of the field of family business studies: Current status and directions for the future. Family Business Review, 17, 1-36.

Sharma, P., Chrisman, J. J., and Chua, J. H. (1997) Strategic management of the family business: Past research and future changes. Family Business Review, 10, 1-35.

Thaler, R. H., and Shefrin, H. M. (1981) An economic theory of self-control, Journal of Political Economy, 89, 391-406. 
Van der Wijst, D. (1989) Financial Structure in Small Business: Theory, Tests and Applications, Berlin: Springer-Verlag.

Van den Berghe, L., \& Carchon, S. (2003) Agency relations within the family business system: An exploratory approach. Corporate Governance, 11, 155-285. 

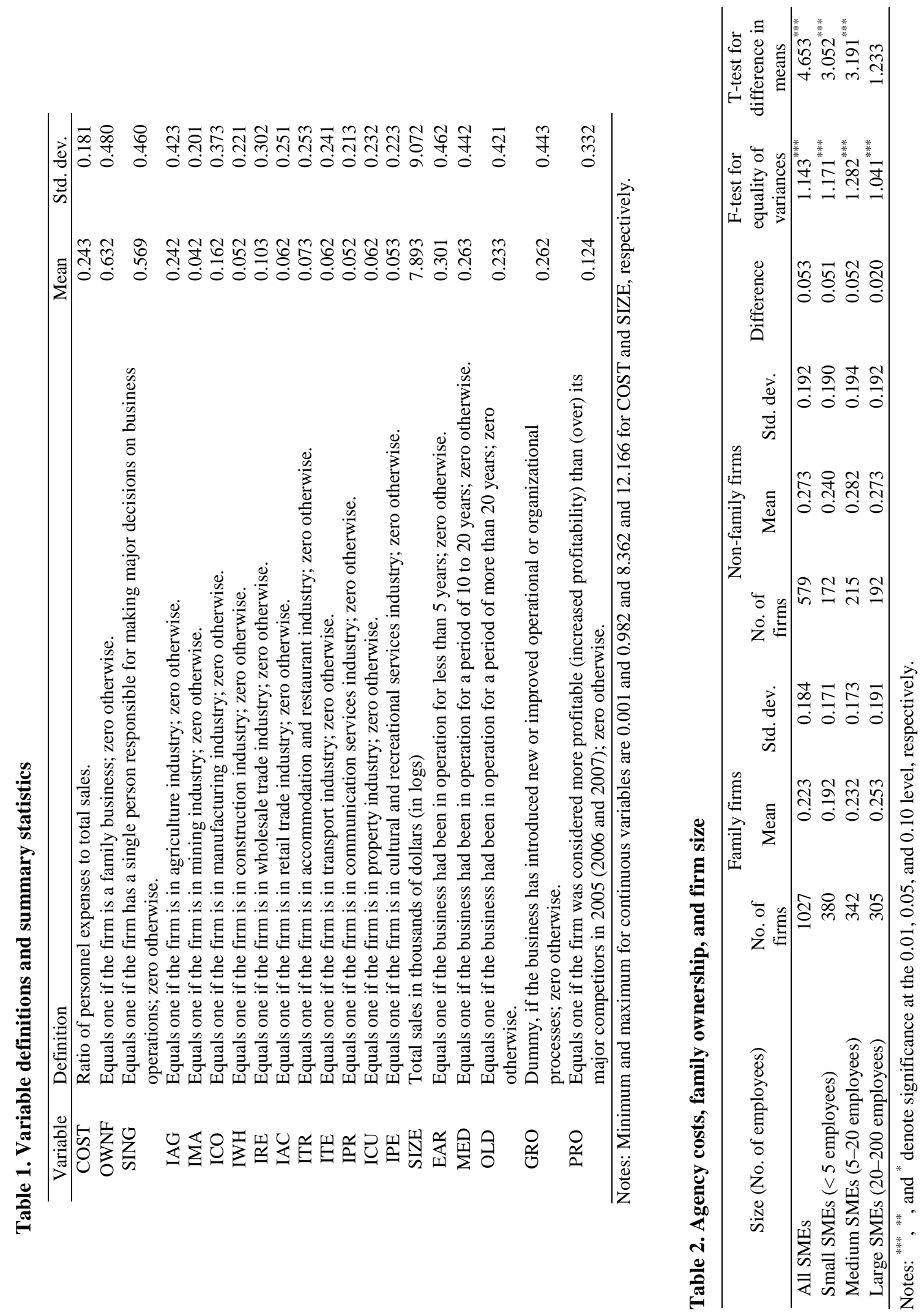


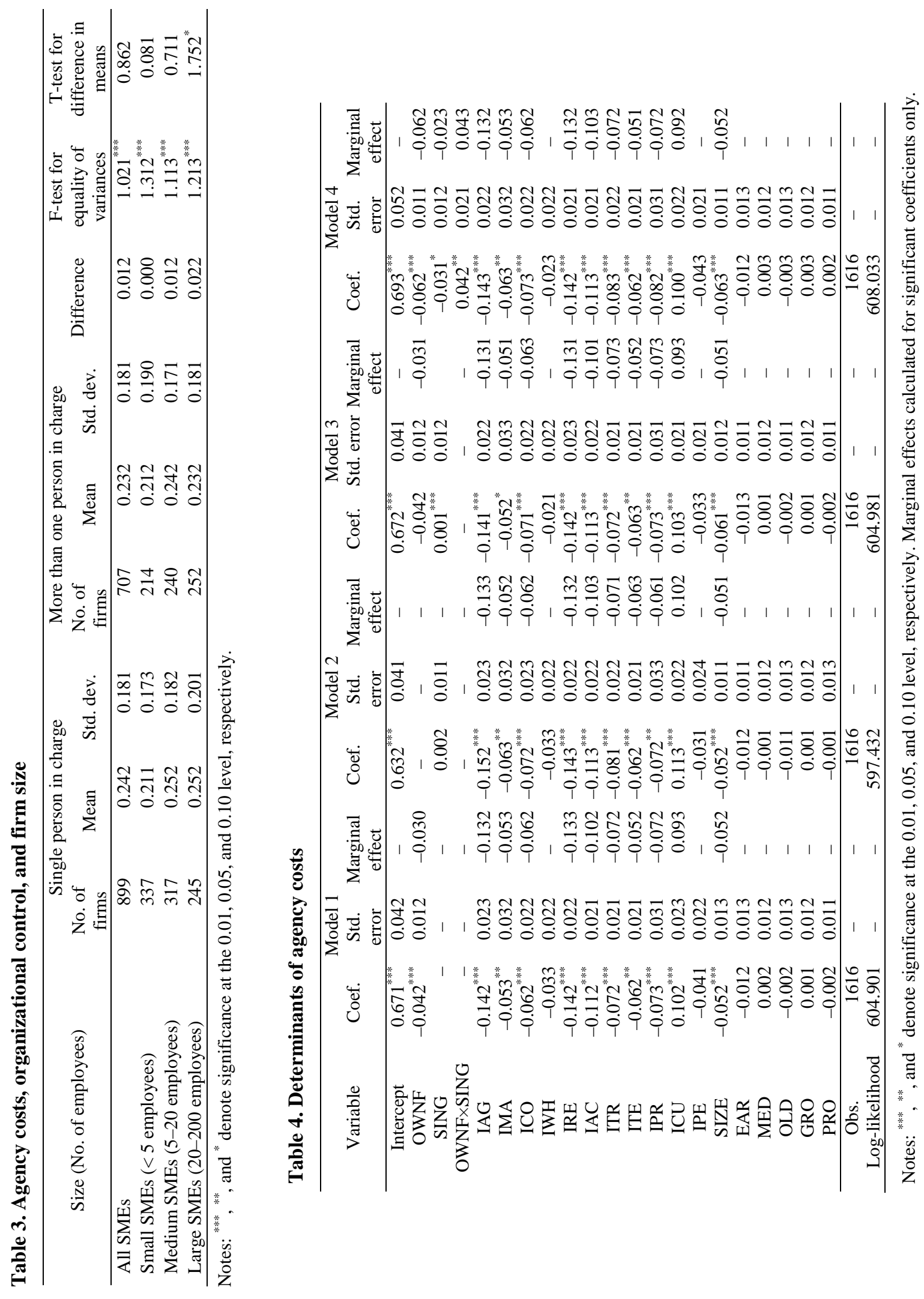




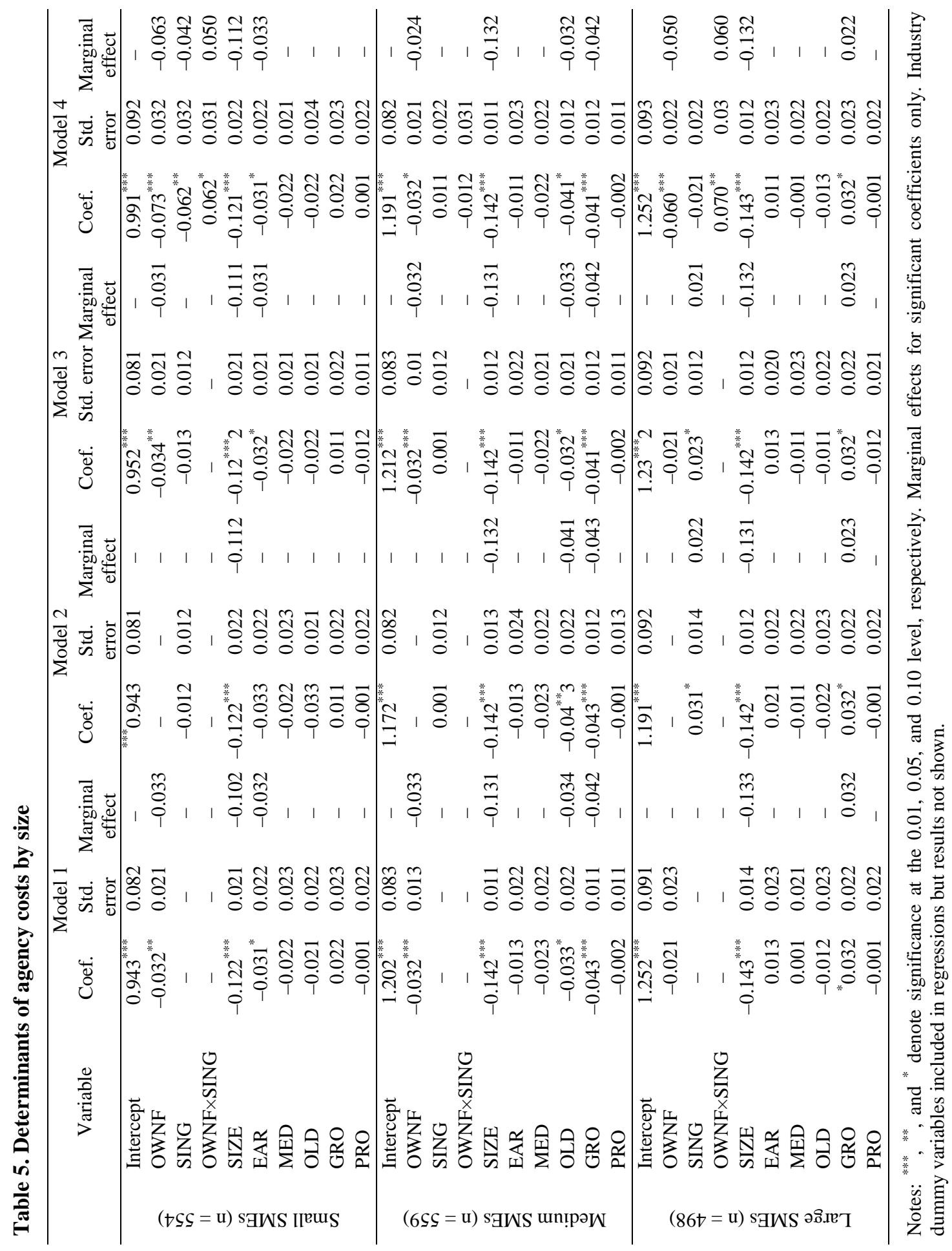


Table 6. Robustness test for determinants of agency costs by size

\begin{tabular}{|c|c|c|c|c|c|c|}
\hline \multirow[b]{2}{*}{ Variable } & \multicolumn{2}{|c|}{ Small SMEs } & \multicolumn{2}{|c|}{ Medium SMEs } & \multicolumn{2}{|c|}{ Large SMEs } \\
\hline & Coef. & $\begin{array}{l}\text { Std. } \\
\text { error }\end{array}$ & Coef. & $\begin{array}{c}\text { Std. } \\
\text { error }\end{array}$ & Coef. & $\begin{array}{l}\text { Std. } \\
\text { error }\end{array}$ \\
\hline Intercept & $1.655^{* * *}$ & 0.241 & $1.762^{* * *}$ & 0.194 & $1.286^{* * *}$ & 0.194 \\
\hline OWNF & $-0.164^{* *}$ & 0.077 & $-0.127^{* *}$ & 0.050 & $-0.146^{* * *}$ & 0.045 \\
\hline SING & $-0.223^{*}$ & 0.174 & -0.063 & 0.050 & -0.063 & 0.049 \\
\hline OWNF $\times$ SING & $0.208^{* *}$ & 0.090 & $0.134^{* *}$ & 0.064 & $0.134^{* *}$ & 0.062 \\
\hline SIZE & $-0.409^{* * *}$ & 0.042 & $-0.381^{* * *}$ & 0.030 & $-0.278^{* * *}$ & 0.029 \\
\hline EAR & -0.081 & 0.054 & -0.040 & 0.046 & -0.024 & 0.050 \\
\hline MED & -0.022 & 0.059 & -0.068 & 0.044 & 0.008 & 0.045 \\
\hline OLD & $-0.109^{*}$ & 0.065 & -0.069 & 0.046 & 0.007 & 0.043 \\
\hline GRO & $0.082^{*}$ & 0.049 & $-0.082^{* *}$ & 0.034 & $0.055^{*}$ & 0.032 \\
\hline PRO & 0.074 & 0.052 & 0.051 & 0.035 & -0.001 & 0.034 \\
\hline Obs. & 554 & & 559 & & 498 & \\
\hline F-value & $9.780^{* * *}$ & & $15.110^{* * *}$ & & $18.400^{* * *}$ & \\
\hline R-squared & 0.264 & & 0.355 & & 0.420 & \\
\hline
\end{tabular}

Notes: ${ }^{* * *},{ }^{* *}$, and ${ }^{*}$ denote significance at the $0.01,0.05$, and 0.10 level, respectively. Industry dummy variables included in regressions but results not shown.

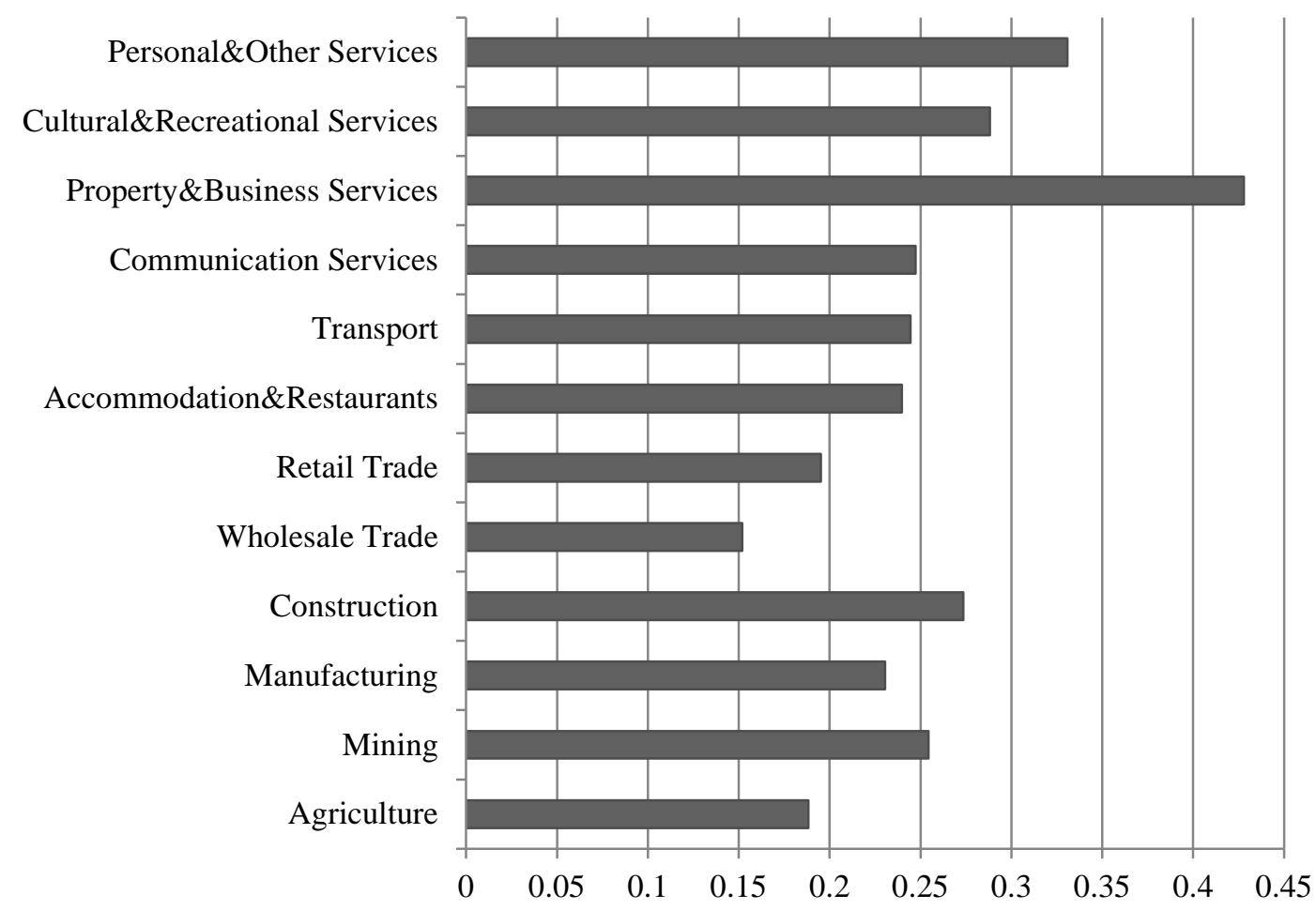

Fig. 1. Expense ratios by industry 


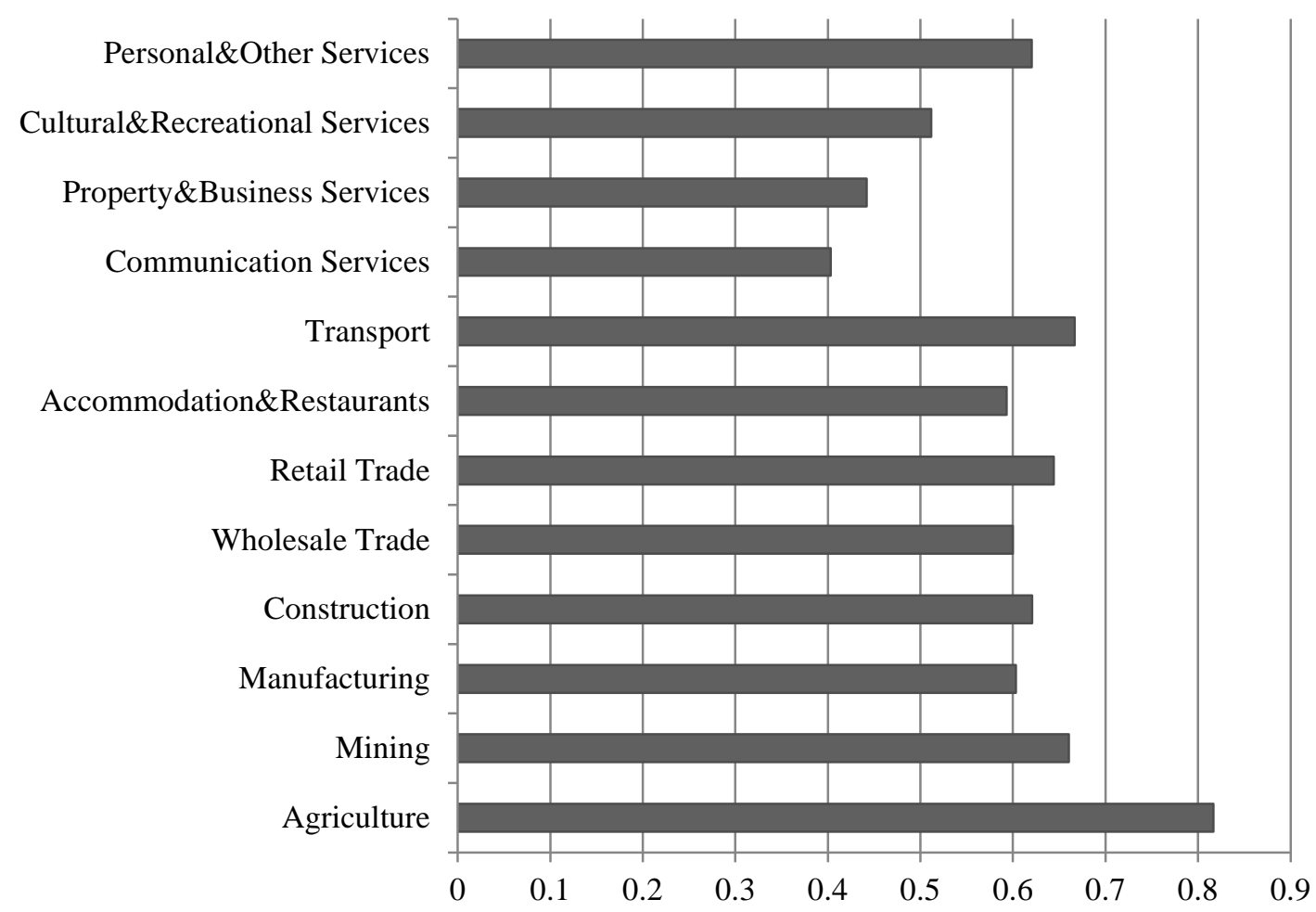

Fig. 2. Proportion of family ownership by industry

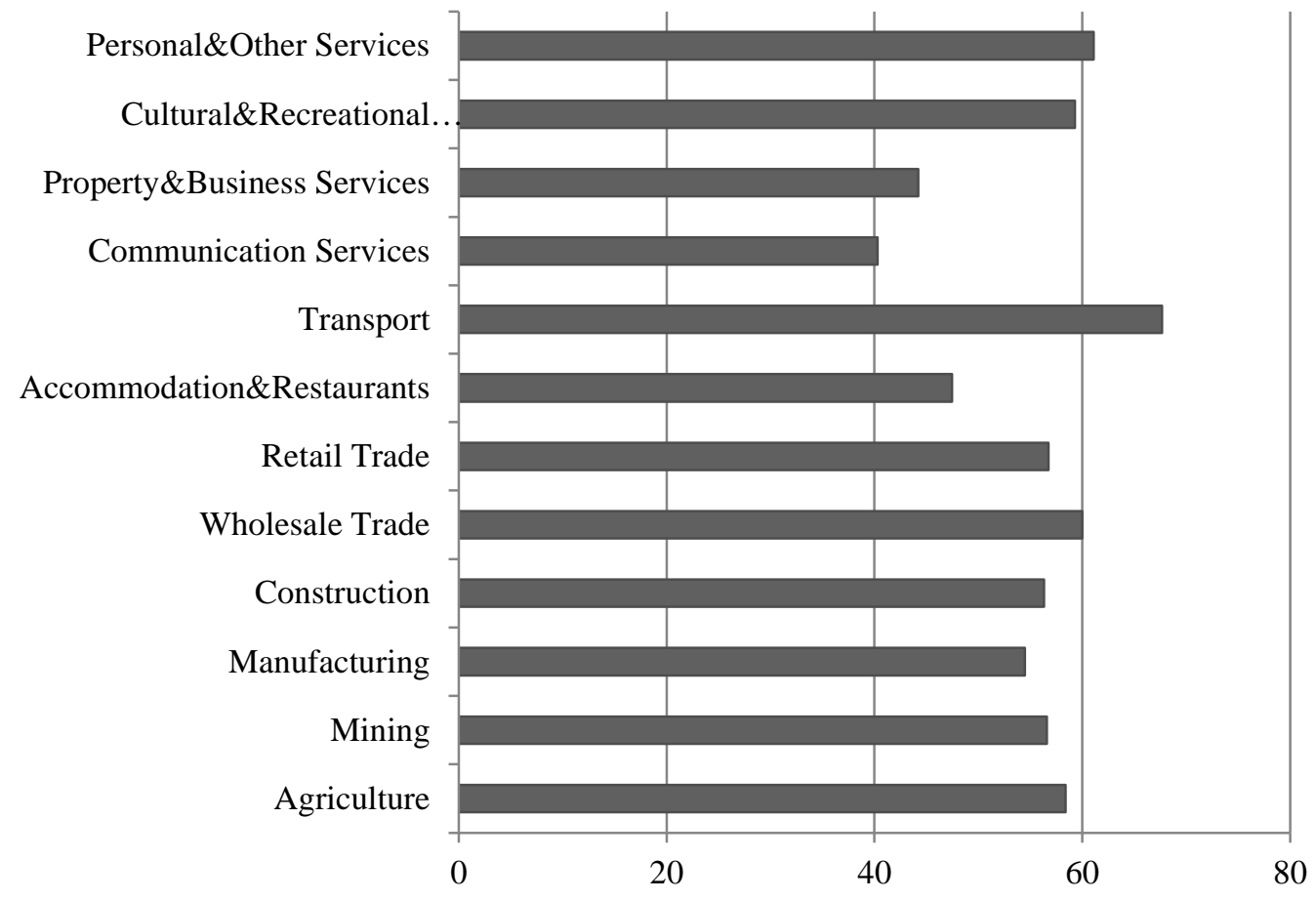

Fig. 3. Proportion of single-person organizational control by industry 